\title{
Mental Training about Aviation Sports Influences on Spatial Orientation of Flying Cadets
}

\author{
Xueshan Song ${ }^{1, a}$ and Liang Cui ${ }^{2, b}$ \\ ${ }^{1}$ Naval Aeronautical and Astroautical University, Yantai, China \\ ${ }^{2}$ Armor Technique Institute of PLA, Changchun, China \\ a294244476@qq.com, b165007605@qq.com
}

\section{Keywords: Spatial orientation; Flying cadets; Psychological training}

\begin{abstract}
Spatial orientation ability refers to the ability of people to judge and understand their attitude, position and movement in space. Weak spatial orientation is an important reason for flight safety. At present, the domestic and foreign training of flight personnel spatial orientation is mainly used in equipment training and instrument training, that is, passive and active training. The application of psychological training to aviation sports training is very rare. The main purpose of this study is introduced by selectively psychological training, as additional training methods of spatial orientation training, research on psychological training plays in cultivating students space flight directional ability, to explore the application of psychological training in spatial orientation training, seek psychological training methods for improving the spatial orientation of flying cadets, for aviation sports teaching reform and innovation of flight training mode provides important scientific basis and theoretical support.
\end{abstract}

\section{Introduction}

The ability of spatial orientation refers to the ability of people to judge and understand their attitude, position and movement in space. Spatial orientation is a serious threat to the safety of flight is a major problem, the world is about $20 \% 30 \%$ to write a class flight accident related to this. In long-term studies, scholars have achieved a consensus that: spatial orientation in flight obstacles, from its essence is the pilot himself, due to lack of psychological and physiological activities in the 3D space motion in the environment. Psychological training refers to the action of special instruments and means of conscious influence on training objects, so that their mental state changes, to achieve the most suitable degree, improve the operating performance, enhance the training to meet the needs of physical and mental health technology. In the spatial orientation of flying cadets training by psychological training is by air sports training form, the use of psychological methods, have influence on purpose and plan their mental processes and personality characteristics, to cultivate good psychological state, the smooth realization of the need to improve the students ability of spatial orientation. The research on improving the spatial orientation of flying cadets by several psychological training methods, to improve the quality of training of flight cadets, improve flight cadets physical fitness to fly for students entering the flight education lay a solid foundation for the body, is of great practical significance to adapt to the future needs of the war, with the strengthening national defense forces[1,2,3].

\section{Psychological Training Methods}

Imagery Training. The imagery training in physical education is a method to improve the motor skill and emotion control ability under the guidance of some kind of hint information. In the theory and practice of imagery training, imagery training is also known as "visual" training, imagery training or imagination training. Imagery training has become a relatively independent psychological training method has been widely used in sports practice, in a number of psychological training and psychological intervention, but also often as an important part of image training. In some foreign sports psychology circles, the imagery training is regarded as the pronoun 
of psychological training. In our country, the sports psychology regards the imagery training as one kind of training method in the psychological training, but is not the representation training and psychological training[4].

Focus on training. Before training, the author inquired about the experience, the effect and the self evaluation of the students' ability of concentration and attention. Focus attention training in the training process.

Method 1: Before the training, the provisions of spatial orientation code, for example in the spin ladder training process, when the body is in the vertical position of the range set for the "1" before the body in 45 degrees as "2" and so on. In the training process, the defender may at any time require the practitioner to indicate the direction of the rotation in the course of rotation. Observe the training situation, and take the method of reducing the rotation speed for the wrong answer or the students who can not answer. When the students answer the correct rate is higher, let the students to combine the action technology and spatial perception of the direction of practice.

Method 2:In the process of practice of students identification signs. In the training process, from the practice of a student with 5 placards 6 meters, billboards were painted “ and other symbols. Let the students identify the signs on the cards during the exercise. Observe the training situation, and take the method of reducing the rotation speed for the wrong answer or the students who can not answer. When the students answer the correct rate is higher, let the students to combine the action technology and spatial perception of the direction of practice.

Psychological suggestion. Psychological suggestion is based on by suggesting no confrontation, no criticism, no resistance, through discussion, facial expressions, gestures, clothing, environment, atmosphere and other favorable conditions, indirectly stimulate by suggesting from the side of the subconscious, and thus affects the influenced psychology and behavior. Psychological test: the story and there is a famous experiment in Psychology: put a piece of wet paper on a subject's skin, and being told that it is a kind of special efficacy of the paper, it can make the local heating of the skin, people feel are stickers that piece of skin temperature change. Ten minutes later, the paper removed, the skin was posted at the end of the red, and eyes touch up fever. In fact, it was just an ordinary wet paper, a psychological suggestion that the local temperature of the skin had changed. The use of that means in the spatial orientation ability in teaching and training, mainly through the transformation of students internal demand and stimulate the students' psychological potential, eliminate or alleviate the psychological burden of students in class, in order to achieve high speed and high quality, the purpose of teaching information transmission[5,6].

\section{Research Objects}

In this study, a Naval Aeronautical and Astroautical University 140 male cadets were randomly selected as the experimental object, formed 1 teams composed of the experimental group, a total of about 70 people; the other 1 construction teams were randomly selected as control group, a total of about 70 people. Subjects were male, aged between 18 and 20 years old, without any professional training history, physical examination qualified. The basic conditions of the subjects are shown in table 1 .

Table 1 The original condition of the object

\begin{tabular}{|l|l|l|l|l|}
\hline Group & Sex & Age & Height $(\mathrm{cm})$ & Weight $(\mathrm{kg})$ \\
\hline $\begin{array}{l}\text { Experience } \\
\text { group }\end{array}$ & Male & $18.33 \pm 1.55$ & $175.66 \pm 4.58$ & $60.35 \pm 4.65$ \\
\hline Matched group & Male & $18.28 \pm 1.63$ & $175.33 \pm 5.46$ & $61.26 \pm 5.16$ \\
\hline
\end{tabular}

Note: the value is expressed as the standard deviation of the mean.

\section{Research Methodology}

Literature Method. Access to relevant information at home and abroad on the psychological training and spatial orientation ability, understand the psychological training characteristics, 
research status and methods of foreign domestic and abroad. The experimental group was given targeted psychological training.

Expert Interviews. Visiting experts and professors of military psychology and spatial orientation ability, provide scientific basis for the implementation of psychological training experiment.

Experimental Control Method. The subjects were divided into two groups: experiment and control. The control group in accordance with the provisions of the training syllabus, the traditional single machine training mode, curriculum implementation and training plan, training content and methods of the basic does not exist randomness and subjectivity. The education and training of the control group by my colleagues, aviation sports teaching and research section of 1 lecturers, the experimental group of education and training by myself. Naval Aeronautical and Astroautical University has a strict military management system, therefore, the experimental group training program and the control group is roughly the same. However, in the implementation of training programs, the experimental group and the control group have the following differences. In each training session, teachers are interspersed with psychological training. The experimental group in the training content and method of randomness, according to the actual situation of the teacher training, such as: emotional, mental state, training atmosphere, etc., the rational selection of psychological training. The psychological training is carried out on the basis of traditional training, the traditional equipment training time to account for more than $75 \%$ of the total training time[7,8].

Mathematical Statistics. The data and results of the experiment and the scale were analyzed by SPSS12.0 software, and the results of the two groups were compared.

\section{Experimental Design}

September 2011 to February 2012, is expected to last 20 weeks.

Experimental Methods. The experimental group was trained with traditional instrument training and psychological training, while the control group was trained according to the traditional teaching method, that is, the traditional training method. Double blind experiment, two groups of students do not know in the experiment, do not know the purpose of the experiment. In the end of the test, the use of blind measurement, that is, the two groups of students together in order to test the order. According to the test results, the two groups were compared. Comparison of the results of the experiment in the control class after the experiment; the experimental class before the experiment the experimental class after the results of comparison: control class before the experiment-control class after the results of the comparison. Through mathematical statistics, to see whether there are significant differences, the difference between the two training methods[9].

Results. In the experimental class and the control class were balancing exercises (down turn), Xuanti practice and practice a fixed wheel achievement test. Test method of balance exercise: turn left 10 seconds and then turn right 10 seconds. The ladder and fixed roller test method: according to the "time air force flight personnel training program" fixed wheel assessment standards. By mathematical statistics, the three indexes reached the level of $\mathrm{P}<0.01$, and the difference was significant. The results are shown in table 2. This shows that the effect of psychological training combined with traditional training programs to improve the ability of spatial orientation is better than the traditional training methods.

Table 2 Comparison of experimental and control classes

\begin{tabular}{|l|l|l|l|}
\hline Project & Balance exercise (C) & Xuanti (S) & Fixed roller (S) \\
\hline Matched group & 28.467 & 68.321 & 58.312 \\
\hline 70 people & 5.341 & 2.613 & 2.012 \\
\hline Experience group & 34.896 & 62.102 & 52.562 \\
\hline 70 people & 4.889 & 1.901 & 4.897 \\
\hline Experience-matched & 6.512 & 6.302 & 2.811 \\
\hline Test & 29.892 & 65.129 & 54.321 \\
\hline P & $<0.01$ & $<0.01$ & $<0.01$ \\
\hline
\end{tabular}


The experimental results show that the two kinds of training methods can improve the spatial orientation ability of the pilots. However, because of the essential difference between the two teaching methods in the application of factors, there is a significant difference between the experimental class and the control class before and after the experiment (see Table 3 and table 4).

Table 3 Comparison of experimental class before and after experiment

\begin{tabular}{|l|l|l|l|}
\hline Project & Balance exercise (C) & Xuanti (S) & Fixed roller (S) \\
\hline Matched group & 25.243 & 75.487 & 62.798 \\
\hline 70 people & 6.034 & 2.061 & 8.856 \\
\hline Experience group & 33.796 & 62.016 & 52.652 \\
\hline 70 people & 4.878 & 1.448 & 4.960 \\
\hline Experience-matched & 8.589 & 13.537 & 10.356 \\
\hline Test & 11.143 & 11.365 & 12.754 \\
\hline P & $<0.01$ & $<0.01$ & $<0.01$ \\
\hline
\end{tabular}

Table 4 Comparison of the results before and after the experiment

\begin{tabular}{|l|l|l|l|}
\hline Project & Balance exercise (C) & Xuanti (S) & Fixed roller (S) \\
\hline Matched group & 25.459 & 75.556 & 62.701 \\
\hline 70 people & 5.336 & 5.065 & 8.679 \\
\hline Experience group & 28.382 & 68.512 & 58.321 \\
\hline 70 people & 5.357 & 4.825 & 4.989 \\
\hline Experience-matched & 3.010 & 7.231 & 4.765 \\
\hline Test & 5.021 & 4.356 & 6.326 \\
\hline P & $>0.01$ & $>0.05$ & $>0.01$ \\
\hline
\end{tabular}

\section{Results Analysis}

Additional Psychological Training can Accelerate the Formation of Motor Skills. Xuanti, fixed wheel and balance exercises are technical. In flying cadets stage of basic education, ladder, fixed wheel and balance the operating results is a major indicator of spatial orientation ability of students. Students should improve the spatial orientation ability, the first is to improve athletic performance and fixed wheel balancing exercises, Xuanti, to improve athletic performance, must be in operation to achieve accurate, skilled. In addition to the experimental class in the training of psychological training and selection of training methods and the training methods, mainly to improve the visual and auditory effects through vision, hearing, memory, thinking, analysis and a series of physiological and psychological process, the accuracy and completeness of the feelings of the object, from the psychological perception of physical exercise to improve. An important objective is to make additional psychological training of students through the things to view, listen carefully, think, access to information, information processing, information sublimation, such information will be transformed into accurate movements of image formation of transient memory, providing good stimulation to accelerate the establishment of correct motor imagery, the movement technology can quickly and accurately form.

A Theoretical Analysis of the Effect of Psychological Training on Improving Spatial Orientation Ability. Ba P Love suggests that the training of suggestion is to regulate the process of the human body by means of the suggestion, that is, the function of the second signal system. For example, the regulation of the people's will, mood, mood and confidence, changes in visceral activity, improve and reduce body temperature, accelerate the metabolism process, etc.. People can accept the hint and the self suggestion, and can adjust the cognitive, emotional and will process through the speech of all things and phenomena which represent the external environment and the internal environment. During the experiment, the students through the combination of training and traditional training that way, not only the external physical activity, and the inner psychological 
activities, students' external activities reflect the students learning the training effect, sports skills, fatigue etc.. The internal psychological activities of students, such as awareness, attention, performance, fear and so on, are directly related to the students' learning and training effect. The students not only master the professional knowledge in learning, but also through sensory information and speech conversion, in the received speech information through understanding, analysis, delete and storage, by using the method of logic thinking, philosophy and method analysis, reasoning, judgment, or the law of sports technology and exploration in learning after repeated problems; the representation of technical action, strengthen the attention to the accuracy and completeness of the technology, to improve the training effect.

\section{Conclusion}

From the Gulf War, Kosovo war, the war in Afghanistan to Iraq, regardless of how to change the style of combat, the air force role in the war has become increasingly prominent, has become a key factor in the outcome of a war; at the same time, flexible machine performance is higher, new aircraft combat radius larger, air dynamic performance is stronger, the future will be more to combat fierce and cruel, all these put forward higher requirements for the constitution. In order to adapt to the new situation of the world military reform, aiming at the need of "winning", as the main body of training the air force, the Naval Aeronautical and Astroautical University will shoulder more important tasks and responsibilities. The stage of basic education (basic cultural learning and physical training stage) flight training will lead the future combat, the air force in the future, it is particularly important to strengthen the education and training of students space flight directional ability in basic education. In this study, to explore the effects of psychological training on spatial orientation of flying cadets, training methods and means to enrich students space flight directional ability, innovation ability of spatial directional training theory, the teaching of "rich theoretical knowledge of aviation sports", expand the application field of mental training, provide a theoretical guarantee for the innovation based on flight training mode to improve the training quality of our military flying cadets, it is very important to strengthen the Air Force combat force.

\section{References}

[1] J.L. Liao. Education and training of spatial disorientation in basic education stage [J]. Journal of Army Aviation Academy.2009.(3).(In Chinese)

[2] L.S. Yu. Advances in research on spatial disorientation in flight [J]. aviation medicine, 2001(2).(In Chinese)

[3] M. Zhu. Flight cadets' psychological quality training [J]. aviation magazine,2007(10).(In Chinese)

[4] L.N.Zi. Sports psychology [M]. Beijing: People's Sports Press,2002.(In Chinese)

[5] Z.W.Li, X.P. Chen.et al. Military sports science [M]. Beijing: Military Science press,1997.(In Chinese)

[6] Neubauer JC. Classifying spatial disorientation mishaps using different efinitions[M].IEEE Eng MedBiol Mag,2000,19(2): 28-34.

[7] Heinle TE. Proeeedings of recent trends in spatial disorientation researeh[M],San Antonio, TX USA.2000.

[8] Lyons TJ, Ereoline WR, Freeman JE, et a1.Classifieation problems of U.S. air Force spatial disorientation accidents[M].Aviat Space Environ Med,1994,65: 1470.152.

[9] Benson AJ, Crawford WR, Davis HE Orientation/ disorientation training of flying Personnel: A working group report. AGARD—R-625.Neuilly sur seine, Franee, 1974. 